\title{
FORMULATION AND EVALUATION OF GASTRORETENTIVE FLOATING TABLET USING HIBISCUS ROSA-SINENSIS MUCILAGE
}

\author{
KHARWADE RS ${ }^{1 *}$, MORE SM${ }^{2}$, MAHAJAN UN ${ }^{1}$ \\ ${ }^{1}$ Department of Pharmaceutics, Dadasaheb Balpande College of Pharmacy, Nagpur, Maharashtra, India. ${ }^{2}$ Department of Pharmacology, \\ Manoharbhai Patel Institute of Pharmacy (B. Pharm), Gondia, Maharashtra, India. Email: rohinismore1@gmail.com
}

Received: 06 December 2016, Revised and Accepted: 21 December 2016

\section{ABSTRACT}

Objective: Domperidone is a synthetic benzimidazole compound that acts as a dopamine $\mathrm{D}_{2}$ receptor antagonist. The main aim of this study was to optimize and evaluate the floating tablets of domperidone that prolongs the gastric residence time using Hibiscus rosa-sinensis mucilage.

Methods: The directly compressible floating tablets of domperidone were formulated using varying amount of hydroxypropyl methylcellulose $\mathrm{K} 100 \mathrm{M}$, carbopol 934P and $\mathrm{H}$. rosa-sinensis mucilage. The effervescent components sodium bicarbonate is used for the generation of $\mathrm{CO}_{2}$ gas. The prepared tablets were evaluated for physicochemical parameters and found to be within range, viz., hardness, swelling index, floating capacity, thickness, and weight variation. Further, tablets were evaluated for in vitro release characteristics. The concentration of $H$. rosa-sinensis mucilage with a gas-generating agent was optimized to get the sustained release of domperidone.

Result: The \% cumulative drug release of all formulation from F1 to F6 was within the range of $81.37 \%$ to $98.62 \%$ for 18 hrs. The release kinetics of all the dosage forms was calculated using zero order, first order, Higuchi, and Korsmeyer-Peppas. It concludes that the release followed zero order release, whereas the correlation coefficient ( $\mathrm{r}^{2}$ value) was higher for zero order release. The release mechanism follows Higuchi model, KorsmeyerPeppas model, and non-Fickian diffusion.

Conclusion: As a result of this study, it may be concluded that the floating tablets using $H$. rosa-sinensis mucilage in optimized concentrations can be used to increase the gastric retention time of the dissolution fluid in the stomach to deliver the drug in a sustained manner. Furthermore, from 1 month stability data shows no significant change compared to initial result.

Keywords: Floating drug delivery, Hibiscus rosa-sinensis mucilage, Domperidone.

(C) 2017 The Authors. Published by Innovare Academic Sciences Pvt Ltd. This is an open access article under the CC BY license (http://creativecommons. org/licenses/by/4. 0/) DOI: http://dx.doi.org/10.22159/ajpcr.2017.v10i3.16494

\section{INTRODUCTION}

Rapid gastrointestinal transit could result in incomplete drug release from the dosage form above the absorption zone leading to diminished efficacy of the administered dose. These considerate have led to the development of a controlled or sustained delivery system. The main purpose for developing these systems was to release the drug slowly into the gastrointestinal tract (GIT) and maintain an effective drug concentration in the systemic circulation for long time. Gastroretentive drug delivery is an approach to prolong gastric retention time, thereby targeting site - specific drug release in the upper GIT for local and systemic effect. Therefore, different approaches have been proposed to retain the dosage form in the stomach. These include bioadhesive systems, swelling and expanding systems and floating systems.

Floating drug delivery or hydrodynamically balanced systems have a sufficient buoyancy to float over the gastric contents and remain buoyant in the stomach without affecting the gastric emptying rate for a prolong period [1-4].

Domperidone is a synthetic benzimidazole compound that acts as a dopamine $\mathrm{D}_{2}$ receptor antagonist. Its localization outside the blood-brain barrier and antiemetic properties other has made it a useful adjunct in therapy for Parkinson's disease. There has been renewed interest in antidopaminergic prokinetic agents since the withdrawal of cisapride, a 5-HT4 agonist, from the market. Domperidone is also used as a prokinetic agent for treatment of upper gastrointestinal motility disorders. Patients receiving domperidone or other prokinetic agents for diabetic gastropathy or gastroparesis should also be managing diet, lifestyle, and medications to optimize gastric motility. After oral administration, domperidone is rapidly absorbed from the stomach and the upper part of the GIT with fewer side effects. It is a weak base with good solubility in acidic $\mathrm{pH}$ but significantly reduced solubility in alkaline medium [5-7]. Such a weak base, formulated as an oral controlled release dosage form is exposed to environments of increasing $\mathrm{pH}$ with subsequent precipitation of poorly soluble free base within the formulation that is no longer capable of being released from the formulation.

A majority of the investigations on natural excipients in drug delivery systems have centered on proteins and polysaccharides due to their ability to produce a wide range of materials and properties according to molecular structural alterations. In recent years, plant gums and mucilages have evoked tremendous interest due to their diverse pharmaceutical applications such as diluents, binders, disintegrants in tablets, thickeners in oral liquids, protective colloids in suspensions, gelling agents in gels and bases in suppository, thus making them attractive substitutes for costly semisynthetic and synthetic excipients. India, due to its geographical and environmental positioning, has traditionally been a good source for such products among the Asian countries. Hibiscus is widely grown as an ornamental plant throughout the tropics and subtropics. The plant is available in India in large quantities. Its 250 species are widely distributed in tropical and subtropical regions of the world and are reported to possess various medicinal properties, viz., antitumor, antihypertensive, and antioxidant. In this study, an effort was made to extract the mucilage from the leaves of Hibiscus rosa-sinensis Linn. and look at the possibility of using this mucilage as the floating agents and releasing retardant material in the formulation of solid dosage forms [8]. 
This study involved the design of gas generating floating tablets of domperidone as a model drug. The gas generating system consists of hydrophilic matrices prepared with the swellable hydrocolloids such as hydroxypropyl methylcellulose (HPMC) K100 M, carbopol 934P and $H$. rosa-sinensis mucilage. The effervescent components sodium bicarbonate was used for the generation of $\mathrm{CO}_{2}$ gas. When the dosage form comes in contact with acidity of gastric contents, the $\mathrm{CO}_{2}$ is entrapped in the polymeric network providing the floating characteristics to the dosage form [9-11].

\section{MATERIAL AND METHODS}

\section{Materials}

Domperidone was generously gifted by Ajanta Pharma Ltd. Mumbai. H. rosa-sinensis leaves are collected from local area of Nagpur, India. Moreover, plant was authenticated at Pharmacognosy Department of Department of Pharmaceutical Science of Nagpur University, India, and mucilage was extracted in Pharmaceutics Research Lab, HPMC K100 M, carbopol 934, sodium bicarbonate, microcrystalline cellulose, magnesium stearate and talc were purchased commercially. All solvents and reagents used were of analytical grade.

\section{Methods}

\section{Extraction of $H$. rosa-sinensis mucilage}

The fresh $H$. rosa-sinensis Linn. leaves were collected and washed with water to remove dirts and debries. Leaves were powdered and soaked in water for 5-6 hrs, boiled for 30 minutes and left stand for $1 \mathrm{hr}$ to allow complete release of mucilage into water. The mucilage was extracted using multi-layer muslin cloth bag to remove the marc from the solution. Acetone (in the volumes of three times to the volume of filtrate) was added to precipitate the mucilage. The mucilage was separated, dried, in an oven at $40^{\circ} \mathrm{C}$, passed through \#80 sieve and stored in dessicator at room temperature for further use $[9,10]$.

\section{Purification of H. rosa-sinensis mucilage}

The crude mucilage $(1 \%)$ was obtained after extraction which was centrifuged at $10000 \mathrm{rpm}$, decanted and precipitated in acetone following 1:2 mucilaginous solution:acetone ratio, washed with isopropyl alcohol with 1:1 volume ratio and finally it was dried $[9,10]$.

\section{Formulation of floating tablet of domperidone by direct} compression

Floating tablets of domperidone were prepared by direct compression method employing sodium bicarbonate as gas generating agent. HPMC $\mathrm{K} 100 \mathrm{M}$ and $\mathrm{H}$. rosa-sinensis mucilage, carbopol 934 were used as a rate controlling polymers. The concentrations of above ingredients were optimized as shown in Table 1 . All the ingredients were weighed accurately. The drug was mixed with the release rate retarding polymers and the mix was blended for 20 minutes to have uniform distribution of drug in the formulation. The blend was lubricated with talc and magnesium stearate and compressed using 8 station compression

Table 1: Formulation batches of floating tablet

\begin{tabular}{lllllll}
\hline \multirow{2}{*}{ Ingredients } & \multicolumn{7}{l}{ Formulation batches } \\
\cline { 2 - 7 } & F1 & F2 & F3 & F4 & F5 & F6 \\
\hline Domperidone & 30 & 30 & 30 & 30 & 30 & 30 \\
HPMC K100 M & 200 & 175 & 175 & 175 & 150 & 100 \\
Hibscus rosa-sinensis & - & - & 50 & 50 & 100 & 125 \\
Mucilage & & & & & & \\
Carbopol & - & 75 & 50 & 25 & 25 & 25 \\
MCC & 110 & 60 & 35 & 60 & 35 & 60 \\
Sodium bicarbonate & 50 & 50 & 50 & 50 & 50 & 50 \\
Magnesium stearate & 5 & 5 & 5 & 5 & 5 & 5 \\
Talc & 5 & 5 & 5 & 5 & 5 & 5 \\
Total weight & 400 & 400 & 400 & 400 & 400 & 400 \\
\hline Alduantities aryyyyyy
\end{tabular}

All quantities are given in mg. MCC: Microcrystalline cellulose,

HPMC: Hydroxypropyl methylcellulose machines. The tablet weighed for compression was adjusted to $400 \mathrm{mg}$ [11].

\section{Evaluation of tablets}

Precompression parameters and characterization of powders

The flow properties of powders (before compression) were characterized in terms of, bulk density, Hausner's ratio, angle of repose, and Carr's index $[4,8]$.

\section{Physical characterization of tablet}

Compressed tablets were then evaluated for shape, diameter and thickness, weight variation, disintegration, hardness, friability study. Diameter and thickness were measured by vernier caliper. Hardness was measured by Monsanto type hardness tester. Friability was determined in friabilator (Electrolab EF-2, USP) $[5,6]$.

\section{Assay of tablets}

Twenty tablets from each batch were weighed and powdered. Powder equivalent to $30 \mathrm{mg}$ of domperidone was accurately weighed and transferred into a $100 \mathrm{ml}$ volumetric flask and dissolved in a suitable quantity of $0.1 \mathrm{~N} \mathrm{HCl}$. The prepared solution was diluted up to $100 \mathrm{ml}$ with $0.1 \mathrm{~N} \mathrm{HCl}$ and sonicated for $60 \mathrm{~min}$. Five milliliters of the resulting solution was diluted to $100 \mathrm{ml}$ with $0.1 \mathrm{~N} \mathrm{HCl}$ to get a concentration in the range of $15 \mu \mathrm{g} / \mathrm{ml}$. A portion of the sample was filtered through $0.45 \mu$ membrane filter and analyzed by Shimadzu UV-1700 UV/Vis double-beam spectrophotometer (Kyoto, Japan) at $284 \mathrm{~nm}[7,12]$.

\section{Floating capacity}

The in vitro buoyancy was determined by floating lag times. The tablets were placed in a $100 \mathrm{ml}$ beaker containing $0.1 \mathrm{~N} \mathrm{HCl}$. The time required for the tablet to rise to the surface and float was determined as floating lag time. The experiments were conducted in triplicate. Total floating times were measured during in vitro dissolution [13-15].

\section{Swelling index}

The extent of swelling was measured in terms of \% of weight gained by the tablet. Three tablets from each formulation was weighed and kept in Petri dish containing $50 \mathrm{ml}$ of $0.1 \mathrm{~N} \mathrm{HCL}$ solution. At the end of specified time interval, tablets were withdrawn from Petri dish and excess buffer was blotted with tissue paper and weighed [13-15].

\section{In vitro dissolution studies}

The release rate of domperidone from floating tablets $(n=3)$ was determined as per British Pharmacopoeia (BP) using dissolution testing apparatus 2 (paddle method). The dissolution test was performed using $900 \mathrm{ml}$ of $0.1 \mathrm{~N} \mathrm{HCl}$, at $37 \pm 0.5^{\circ}$ and $50 \mathrm{rpm}$. A sample ( $\left.5 \mathrm{ml}\right)$ of the solution was withdrawn from the dissolution apparatus hourly for $24 \mathrm{hrs}$, and the samples were replaced with fresh dissolution medium. The samples were filtered through $0.45 \mu$ membrane filter and diluted to a suitable concentration with $0.1 \mathrm{~N} \mathrm{HCl}$. Absorbance of these solutions was measured at $284 \mathrm{~nm}$ using a Shimadzu UV-1700 UV/V is double-beam spectrophotometer (Kyoto, Japan). Duration of time the tablets constantly float on dissolution medium was noted as total floating time [5-7,12].

Kinetic analysis of in vitro release rate of floating tablets of domperidone

The rate and mechanism of release of domperidone from the prepared floating tablets were analyzed by fitting the dissolution data into following equations:

Zero order kinetics $\mathrm{F}=\mathrm{k}_{0} \mathrm{t}$

First order kinetics $(1-\mathrm{F})=-\mathrm{k}_{1} \mathrm{t}$

To describe the drug release behavior from polymeric systems, the dissolution data were also fitted according to the well-known exponential Korsmeyer-Peppas equation.

$\mathrm{M}_{\mathrm{t}} / \mathrm{M}_{\infty}=\mathrm{Kt}^{\mathrm{n}}$ 
Where, $\mathrm{M}_{t} / \mathrm{M}_{\infty}$ is the fraction of drug release at time $\mathrm{t}$ and $\mathrm{k}$ is the kinetic constant, $\mathrm{n}$ is the release exponent (indicating the general operating release mechanism) $[15,16]$.

For tablets, depending on the aspect ratios values between 0.43 and 0.5 indicating Fickian (case I) diffusion-mediated release, non-Fickian (Anomalous) release, coupled diffusion, and polymer matrix relaxation, occurs if $0.5<\mathrm{n}<0.89$, purely matrix relaxation or erosion-mediated release occurs for $n=1$ (zero order kinetics), and super case II type of release for $\mathrm{n}>0.89$.

\section{Statistical analysis}

To evaluate contribution of each factor with different levels on responses, two-way analysis of variance was performed using SigmaStat software (SigmaStat 2.03, SPSS, Chicago, Illinois, USA).

\section{Stability studies}

The optimized formulation was kept for short-term stability study. The conditions for stability were $30^{\circ} \mathrm{C} \pm 2{ }^{\circ} \mathrm{C}$ room temperature and relative humidity of $65 \% \mathrm{RH} \pm 5 \% \mathrm{RH}$. All tablets were suitably packed in group of 10 in aluminum foil. At the end of one month, the sealed tablets were opened and evaluated for in vitro release and in vitro floating.

\section{RESULTS}

\section{Precompression parameters}

The domperidone powder mixtures obtained during the precompression process were subjected to different parameters and the results were represented in Table 2 .

\section{Postcompression parameters}

Weight variation data of the prepared tablets indicated no significant difference in the weight of individual tablet from the average value. Hardness of the prepared tablets was observed to be within the range of $3.9-4.7 \mathrm{~kg} / \mathrm{cm}^{2}$. Thickness of all the tablets was found in the range of $3.23-3.45 \mathrm{~mm}$. Friability of all the tablets was found below $1 \%$ was shown in Table 3 .

The drug content in all the batches of domperidone floating tablets was in the range of $98-100 \%$ which is within the specified IP limit. This ensured the uniformity of the drug content in the tablets represented in Table 4.

\section{Swelling index and floating lag time}

The swelling index results were depicted in Table 4. It was observed that the swelling indexes were increased with increasing $H$. rosa-sinensis gum concentration with carbopol than that of ones containing HPMC $\mathrm{K} 100 \mathrm{M}$ alone because of the fact that the H. rosa-sinensis and carbopol are more viscous in nature and showed good swelling properties in the later periods $[8,13]$. The formulations had desired floating lag time ( $<80$ seconds) and total floating time between 12 and $18 \mathrm{hrs}$ was found to be the function of concentration of gum.

\section{In vitro dissolution study}

The \% cumulative drug releases of all formulations from F1 to F6 were within the range of $81.37-98.62 \%$ for 18 hrs (Fig. 1). From results of in vitro drug release studies, it concludes that $\mathrm{F} 6$ had better sustained release than the other formulation (Fig. 1). To analyze the domperidone release mechanism, the in vitro release data were fitted into various release equations and kinetic models (first order, zero order, Higuchi, Korsmeyer-Peppas) as indicated by the value of $\mathrm{r}^{2}$, the Higuchi model was found to be efficient in describing the diffusion mechanism. To explore the release pattern, results of the in vitro release data of all formulations were fitted to the Korsmeyer-Peppas equation showed " $n$ " value between 0.56 and 0.76 that indicate the drug release occurred via non-Fickian diffusion mechanism (Table 5).

\section{Stability study}

The results of stability study indicated that there were no significant changes in drug content, floating lag time, and floating time (Table 6).

Table 2: Precompression parameters of formulations

\begin{tabular}{|c|c|c|c|c|c|}
\hline Formulation code & Angle of repose $(\theta)$ & Bulk density (g/cc) & Tapped density (g/cc) & Compressibility index & Hausner's ratio \\
\hline $\mathrm{F} 1$ & $25.32 \pm 0.181$ & $0.68 \pm 0.042$ & $0.75 \pm 0.026$ & $9.45 \pm 0.065$ & $1.01 \pm 0.013$ \\
\hline $\mathrm{F} 2$ & $25.21 \pm 0.248$ & $0.69 \pm 0.036$ & $0.74 \pm 0.029$ & $9.92 \pm 0.028$ & $1.12 \pm 0.077$ \\
\hline F3 & $26.90 \pm 0.713$ & $0.69 \pm 0.026$ & $0.80 \pm 0.091$ & $10.34 \pm 0.022$ & $1.07 \pm 0.017$ \\
\hline F4 & $24.47 \pm 0.279$ & $0.70 \pm 0.061$ & $0.79 \pm 0.036$ & $9.32 \pm 0.037$ & $1.09 \pm 0.051$ \\
\hline F5 & $26.56 \pm 0.423$ & $0.68 \pm 0.047$ & $0.79 \pm 0.047$ & $13.45 \pm 0.048$ & $1.11 \pm 0.099$ \\
\hline F6 & $26.91 \pm 0.576$ & $0.67 \pm 0.036$ & $0.78 \pm 0.032$ & $12.62 \pm 0.053$ & $1.07 \pm 0.031$ \\
\hline
\end{tabular}

Mean \pm SD, $n=3, p<0.05$. SD: Standard deviation

Table 3: Postcompression parameters-I of tablets

\begin{tabular}{lllr}
\hline Formulation code & Weight variation & Thickness $(\mathbf{m m})$ & Hardness $\left(\mathbf{k g} / \mathbf{c m}^{2}\right)$ \\
\hline F1 & $399.27 \pm 1.181$ & $3.24 \pm 0.036$ & $4.4 \pm 0.381$ \\
F2 & $400.02 \pm 3.223$ & $3.38 \pm 0.091$ & $3.9 \pm 0.296$ \\
F3 & $400.16 \pm 1.293$ & $3.40 \pm 0.073$ & $4.2 \pm 0.577$ \\
F4 & $400.46 \pm 1.173$ & $3.43 \pm 0.082$ & $4.7 \pm 0.122$ \\
F5 & $401.03 \pm 2.283$ & $3.45 \pm 0.069$ & $4.6 \pm 0.091$ \\
F6 & $399.36 \pm 1.132$ & $3.29 \pm 0.089$ & $4.7 \pm 0.178$ \\
\hline
\end{tabular}

mean $\pm S D, n=3, p<0.05$. SD: Standard deviation

Table 4: Postcompression parameters-II of tablets

\begin{tabular}{llll}
\hline Formulation code & Drug content (\%) & Floating lag time (s) & Swelling index (\%) \\
\hline F1 & $98.23 \pm 0.15$ & 70 & $29.29 \pm 0.13$ \\
F2 & $99.76 \pm 0.21$ & 66 & $30.09 \pm 0.15$ \\
F3 & $99.81 \pm 0.18$ & 64 & $33.62 \pm 0.05$ \\
F4 & $98.48 \pm 0.07$ & 64 & $33.68 \pm 0.18$ \\
F5 & $98.69 \pm 0.19$ & 60 & $35.96 \pm 0.19$ \\
F6 & $99.57 \pm 0.18$ & 55 & $38.23 \pm 0.12$ \\
\hline
\end{tabular}

Mean $\pm S D, n=3, p<0.05$. SD: Standard deviation 
Table 5: Dissolution kinetics of domperidone floating tablet

\begin{tabular}{|c|c|c|c|c|c|c|}
\hline \multirow[t]{2}{*}{ Formulation code } & \multicolumn{3}{|l|}{$\mathbf{r}^{2}$} & \multicolumn{2}{|c|}{ Korsmeyer-Peppas } & \multirow[t]{2}{*}{ Drug release mechanism } \\
\hline & Zero order & First order & Higuchi & $\mathbf{r}^{2}$ & Slope (n) & \\
\hline F1 & 0.8205 & 0.9543 & 0.9703 & 0.9553 & 0.5621 & First order non-Fickian diffusion \\
\hline F3 & 0.9002 & 0.9555 & 0.9729 & 0.9808 & 0.5368 & First order non-Fickian diffusion \\
\hline F4 & 0.9509 & 0.8426 & 0.9694 & 0.9791 & 0.5831 & Zero order non-Fickian diffusion \\
\hline F5 & 0.9646 & 0.8724 & 0.9726 & 0.9884 & 0.6238 & Zero order non-Fickian diffusion \\
\hline F6 & 0.9780 & 0.8632 & 0.9484 & 0.9685 & 0.7892 & Zero order non-Fickian diffusion \\
\hline
\end{tabular}

Table 6: Drug content and floating behavior of optimized F6 formulation during short-term stability study

\begin{tabular}{ll}
\hline Parameter & Result \\
\hline Drug content & $98.42 \pm 0.15 \%$ \\
Floating lag time & $63 \mathrm{~s}$ \\
Floating time & $18 \mathrm{~h}$ \\
\hline
\end{tabular}

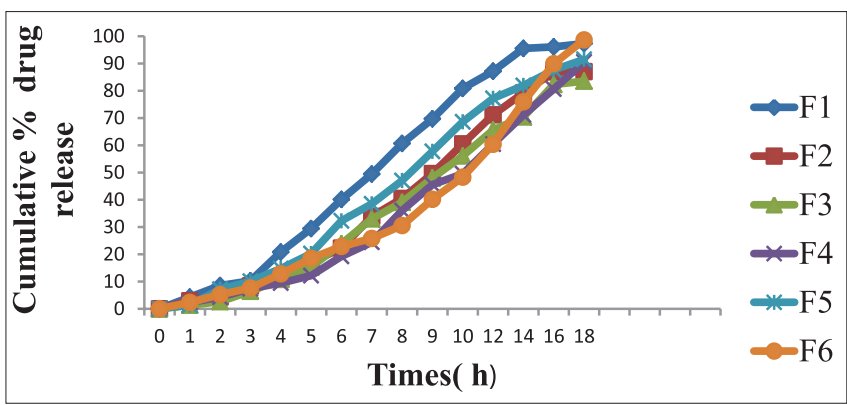

Fig. 1: Cumulative in vitro drug release profile of domperidone (mean \pm standard deviation, $\mathrm{n}=3, \mathrm{p}<0.05$ )

\section{DISCUSSION}

From the results of precompression parameter of tablet it was observed that the bulk density was found to be between 0.672 and $0.703 \mathrm{~g} / \mathrm{ml}$ and the tapped density ranged between 0.747 and $0.824 \mathrm{~g} / \mathrm{ml}$, which make them floatable in the gastric fluid. The other micromeritic properties such as Carr's index, Hausner's ratio revealed no significant differences. Angle of repose was to be between 24.35 and 26.91 indicating good flow properties. Hardness, friability, weight variation, thickness, disintegration time of tablet formulation were within acceptable limits and the drug content in all the batches of domperidone ensured the uniformity of the drug content in the tablets.

The result of floating lag time demonstrates that the tablets containing $H$. rosa-sinensis gum alone showed longer floating lag time as the tablets tend to disintegrate due to the fast release of $\mathrm{CO}_{2}$ gas. This may be because of the fact that at lower concentrations, the gum has lesser ability to form as gel. This was mainly due to the evolution of $\mathrm{CO}_{2}$ entrapped into the matrix of swollen polymer of the matrix and well protected by gel formation by the hydrated polymer resulting from interaction between the gas generating agent (sodium bicarbonate) and dissolution medium $(0.1 \mathrm{~N} \mathrm{HCl}$ with $\mathrm{pH} 1.2)$ that leads to lowering the density and enabling the tablet to float $[13,14]$.

The results revealed that as the amount of $H$. rosa-sinensis mucilage increased, the \% swelling increased. This result may be explained by the hydrophilic nature $H$. rosa-sinensis gum which when present at optimum concentration with HPMC, rapidly hydrates leading to expansion and consequently an ordering of the polymer chains. Tablets containing carbopol 934 as copolymer (especially F6) showed higher $\%$ swelling. It was reported that carbopol swells in simulated gastric fluid, $\mathrm{pH}$ 1.2. The amount of effervescent mixture incorporated had a significant effect on swelling properties of tablet. This may be due to the increased reaction of sodium bicarbonate with the dissolution medium that increased the release of $\mathrm{CO}_{2}$ and consequently, the number of pores and swelling index was increased [16-19].

In vitro dissolution data of formulation (F1 to F6) reported in Fig. 1. The overall drug releases from these tablets are governed by burst effect followed by gel layer formation, drug diffusion into the gel layer and to the dissolution media. These considerations indicate that hydrophilic polymers have the potential to sustain the release of drug from tablet. Polymer HPMC K100 yielded a faster initial burst effect with desirable drug release. The additional use of carbopol and $H$. rosa-sinensis mucilage decreased the release of domperidone from the tablet. Likely due to the fact that carbopol and H. rosa-sinensis are cross-linked polymers when contacted with water, it would swell and hold water inside its microgel network. By increasing the mucilage percentage, a viscous gel layer is formed and diffusion of the drug is controlled primarily by the gel viscosity. The viscosity of mucilage solutions strongly increases with increasing concentration of the mucilage. The behavior is attributable to the intermolecular interaction, increasing the effective macromolecule dimensions and molecular weight $[5,6]$.

\section{CONCLUSIONS}

In this study, gastroretentive floating tablets of domperidone were successfully prepared by direct compression method using H. rosa-sinensis mucilage. Fabricated tablets showed acceptable weight variation, hardness, and uniformity of drug content. The overall results explained that the tablets prepared by combination of $H$. rosa-sinensis mucilage, HPMC K100 M, carbopol and gas-generating agent sodium bicarbonate, could be more efficient on floating and sustained release of domperidone as compared to the tablets prepared using HPMC K100 $\mathrm{M}$ and carbopol only. Thus, proper selection of the ratio of desired drug release was achievable.

\section{REFERENCES}

1. Rouge N, Leroux JH, Cole ET, Doelker E, Buri P. Prevention of the sticking tendency of buoyant minitablets filled into hard gelatine capsules. Eur J Pharm Biopharm 1997;43(2):165-71.

2. Lee JH, Park TG, Choi HK. Development of oral drug delivery system using floating microspheres. J Microencapsul 1999;16(6):715-29.

3. Robinson JR, Eriksen SP. Theoretical formulation of sustained-release dosage forms. J Pharm Sci 1966;55(11):1254-63.

4. Baumgartner S, Kristl J, Vrecer F, Vodopivec P, Zorko B. Optimisation of floating matrix tablets and evaluation of their gastric residence time. Int J Pharm 2000;195(1-2):125-35.

5. Manmohan SJ, Anshita G, Abhishek KS. Development and evaluation of mucoadhesive sustained release tablet using Tamarindus indica Gum. Asian J Res Pharm Sci 2014;4(2):77-82.

6. Sajid KS, Kamran AC, Ullah R, Hussain Z, Sadozai KM, Rahman US, et al. Formulation development and evaluation of domperidone sustained release matrix tablets by two different methods using guar gum as a sustaining agent. World Appl Sci J 2013;25(12):1704-12.

7. Khan MA, Saeed M, Badshah A, Muhammad N, Khan J, Khan FA, et al. Design, formulation, optimization and evaluation of sustained release tablets of domperidone. Afr J Pharm Pharmacol 2011;5(16):1882-7.

8. Ameena K, Dilip C, Saraswathi R, Krishnan PN, Sankar C, Simi SP. Isolation of the mucilages from Hibiscus rosa-sinensis Linn. And Okra (Abelmoschus esculentus Linn.) And studies of the binding effects of the mucilages. Asian Pac J Trop Med 2010;3(7):539-43. 
9. Senapati K, Srinatha A, Pandit JK. In vitro release characteristics of matrix tablets: Study of Karaya gum and Guar gum as release modulators. Indian J Pharm Sci 2006;68(6):824-6.

10. Girish KJ, Dhiren PS, Vipul DP, Vineet CJ. Gums and mucilages: Versatile excipients for pharmaceutical formulations. Asian J Pharm Sci 2009;4(5):309-23.

11. Streubel A, Siepmann J, Bodmeier R. Floating matrix tablets based on low density foam powder: Effects of formulation and processing parameters on drug release. Eur J Pharm Sci 2003;18(1):37-45.

12. Krögel I, Bodmeier R. Development of a multifunctional matrix drug delivery system surrounded by an impermeable cylinder. J Control Release 1999;61(1-2):43-50.

13. Khullar P, Khar RK, Agarwal SP. Evaluation of hydrogelbased controlled-release niacin tablets. Drug Dev Ind Pharm 1998;24(5):479-83.

14. Chavanpatil M, Jain P, Chaudhari S, Shear R, Vavia P. Development of sustained release gastro-retentive drug delivery system for ofloxacin:
In vitro and in vivo evaluation. Int J Pharm 2005;304(1-2):178-84

15. Dey S, Dutta S, Mazumder B. Formulation and evaluation of floating matrix tablet of atenolol for gastro-retentive drug delivery. Int J Pharm Pharm Sci 2012;4(3):433-7.

16. Shunmuga VJ, Lakshmanan P, Basker RD. Formulation development and characterization of Hibiscus rosa-sinesis dry leaves mucilage as smart polymer for pharmaceutical use. Int J Appl Res Nat Prod 2015;8(2):28-36.

17. Sowjanya K, Deepthi KS, Bharathi A. Formulation and evaluation of gastro-retentive floating matrix tablets of nevirapine. Int J Pharm Pharm Sci 2012;4(5):368-75.

18. Higuchi T. Mechanism of sustained-action medication. Theoretical analysis of rate of release of solid drugs dispersed in solid matrices. J Pharm Sci 1963;52:1145-9.

19. Peppas NA, Sahlin JJ. A simple equation for description of solute release. III. Coupling of diffusion and relaxation. Int $\mathrm{J}$ Pharm 1989;57:169-71. 